Geopolítica(s) Revista de estudios sobre espacio y poder ISSN: 2172-3958

https://dx.doi.org/10.5209/geop.74512

\title{
La implicación estadounidense en la guerra contra el Frente Polisario en la década de 1980
}

\section{Domingo Garí ${ }^{1}$}

Recibido: 28 de febrero de 2021 / Aceptado: 2 de junio de 2021

Resumen. Con este trabajo se pretende clarificar cuál fue la posición de EE UU en la guerra entre Marruecos y el Sáhara Occidental durante la década de los años ochenta del siglo pasado. La elección de ese momento y el tema se deben a que fueron los años claves para el devenir de la contienda. La implicación de EE UU provocó que el Polisario no pudiese ganar la guerra y constituir su estado independiente. Para llevar a cabo este trabajo se utilizó, principalmente, la documentación de servicios secretos y diplomáticos norteamericanos. Además, se usaron trabajos procedentes de distintos investigadores académicos y militares estadounidenses. Se ha hecho un análisis de los textos primarios, y luego han sido confrontados con la literatura disponible que trata el tema. Las conclusiones apuntan a que la implicación norteamericana, y la de muchos de sus socios, fue la causante de una prolongada guerra en el Sáhara Occidental y de que aún permanezca sin resolverse el asunto de los campos de refugiados, así como que la soberanía sobre el territorio siga estando en disputa. La gran ayuda recibida por el reino de Marruecos no fue suficiente para que Hasán II pudiese alzarse con la victoria militar.

Palabras clave: Estados Unidos; Sáhara Occidental; Marruecos; guerra; imperialismo.

\section{[en] American Involvement in the War against the Polisario Front in the $1980 \mathrm{~s}$}

\begin{abstract}
The aim of this work is to clarify the position of the United States in the war between Morocco and Western Sahara during the 1980s. The choice of that moment and the topic are due to the fact that they were the key years for the future of the contest. The involvement of the United States meant that the Polisario could not win the war and constitute its independent state. To carry out this work, the documentation of US secret and diplomatic services was used mainly. In addition, papers from different American military and academic researchers were used. An analysis of the primary texts has been made, and then they have been compared with the available literature that deals with the issue. The conclusions suggest that the North American involvement, and of many of its allies, was the cause of a prolonged war in the Western Sahara, and that the issue of the refugee camps, as well as that of sovereignty over the territory remains in dispute. The great help received by the kingdom of Morocco was not enough for Hasan II to achieve a military victory.
\end{abstract}

Keywords: USA; Western Sahara; Morocco; war; imperialism.

1 Universidad de La Laguna (España).

Email: dhayek@ull.es

https://orcid.org/0000-0002-8139-3365 
[pt] O envolvimento norte-americano na guerra contra a Frente Polisário na década de 1980

\begin{abstract}
Resumo. O objetivo deste trabalho é esclarecer a posição dos Estados Unidos na guerra entre o Marrocos e o Saara Ocidental durante a década de oitenta do século passado. A escolha daquele momento e do tema se deve ao fato de terem sido os anos-chave para o futuro da contenda. O envolvimento dos Estados Unidos fez com que a Polisário não pudesse ganhar a guerra e constituir o seu estado independente. Para realizar este trabalho, utilizou-se principalmente a documentação dos serviços secretos e diplomáticos dos Estados Unidos. Além disso, foram usados artigos de diferentes pesquisadores militares e acadêmicos americanos. Foi feita uma análise dos textos primários e, em seguida, os comparamos com a literatura disponível que trata do assunto. As conclusões sugerem que o envolvimento norteamericano, e de muitos de seus parceiros, foi a causa de uma prolongada guerra no Saara Ocidental, e motivo para que a questão dos campos de refugiados, bem como a soberania sobre o território permaneça em disputa. A grande ajuda recebida pelo reino do Marrocos não foi suficiente para Hasan II alcançar a vitória militar.
\end{abstract}

Palavras-chave: Estados Unidos; Saara Ocidental; Marrocos; guerra; imperialismo.

Sumario. Introducción. 1. Un largo conflicto no resuelto. 2. La iniciativa relativamente moderada del gobierno Carter. 3. Las justificaciones estratégicas del gobierno de Reagan. 4. El apoyo material. Conclusiones. Referencias.

Cómo citar: Garí, D. (2021). La implicación estadounidense en la guerra contra el Frente Polisario en la década de 1980. Geopolítica(s). Revista de estudios sobre espacio y poder, 12(2), 255-276. https://dx.doi.org/10.5209/geop.74512

\title{
Introducción
}

La guerra en el Sáhara Occidental se inició tras una nefasta política de descolonización del gobierno de Madrid (Villar, 1982; De Dalmases, 2010; Bárbulo, 2017). El inicio de la Marcha Verde en el año 1976 supuso el comienzo de la ocupación del territorio por el reino de Marruecos. La guerra se desató con virulencia extrema por parte de las fuerzas ocupantes, lo que motivó la huida apresurada de la población del Sáhara hacia la frontera argelina (Hodges, 1984; Martín Beristain y González Hidalgo, 2009; Martín Beristain, Martínez Torres, Valencia Villa y Campos Lladó, 2015). Los guerrilleros saharauis agrupados en el Frente Polisario iniciaron un contraataque rápido. Los saharauis ganaron terreno y aumentaron su zona de control militar. Su fuerza militar y diplomática creció gracias al apoyo internacional y al respaldo permanente de Argelia, principal garante de la causa saharaui, y país de prestigio consolidado en los foros internacionales $\mathrm{y}$, en concreto, en las organizaciones que agrupaban a los países no alineados (Ahmed Omar, 2017).

Los últimos años de la década del setenta, el Polisario avanzó y mostró un atrevimiento cada vez mayor. Marruecos, sumergido en crisis internas de naturaleza económica, política y militar fue incapaz de contener las ofensivas militares de los guerrilleros. No bastaba el apoyo de países ricos y de ayudas muy generosas dispensadas por Arabia Saudita, Francia o Estados Unidos, para garantizar el triunfo de la ocupación (Balta, 1994; Damis, 1983; Hughes, 2001).

Durante el gobierno Carter la ayuda americana se mantuvo, pero estaba sujeta a determinadas condiciones, y no significaba una carta blanca al militarismo marroquí. 
Los franceses, sauditas, israelíes, kuwaitíes y los Emiratos dieron mucho dinero y apoyo a la causa de Hasán II. Sin embargo, no fue hasta la llegada de los republicanos al gobierno de EE UU en 1981, cuando Marruecos gozó de unas excelentes ayudas militares y financieras por parte de los norteamericanos.

Con la llegada de Reagan al poder la guerra cambió de suerte, y desde entonces los saharauis comenzaron a perder la iniciativa. EE UU justificó su apoyo resuelto a la causa marroquí aduciendo tres razones principales. La primera, que ponían fin a la política timorata de Carter en el exterior, a quien se le consideraba responsable de haber sumido a EE UU en la depresión después de la retirada de Vietnam. Los republicanos querían volver al centro de la política internacional y dejar atrás el amargo recuerdo de la derrota en Vietnam. La segunda razón era que temían un contagio del islamismo político tras el triunfo de la revolución de los ayatolás en Irán. Reagan pensaba que debía sostener a Hasán II a toda costa, porque lo veía como un factor de estabilidad en un país geográficamente clave, dado que estaba al sur de los países europeos miembros de la OTAN y compartía con estos el acceso al mar Mediterráneo. La tercera razón se inscribió en la confrontación con la URSS en el norte de África, zona en la que los soviéticos contaban con presencia e intereses propios. EE UU temía que un futuro Estado saharaui cayese en manos de Moscú y, en su visión de suma cero, estaba dispuesto a impedirlo (Damis, 1993; Zoubir y Amirah-Fernández, 2008).

Tras esas razones estratégicas, descontada la importante ayuda económica y militar que EE UU dispensó a Marruecos, la construcción de los muros se tornó en un factor clave para cambiar el rumbo de la contienda. En el origen de esta estrategia se encuentra Francia, extrapolando las enseñanzas sobre la guerra de guerrillas inspiradas en Mao y aprendidas y sufridas en Vietnam y Argelia.

El trabajo se ha secuenciado en tres partes. La primera se centra en el momento final del gobierno de Carter, y cómo este presidente fue aumentando su apoyo a Marruecos tras la revolución iraní de 1979, a pesar de que diplomáticamente mantenía una simulada imparcialidad. Luego se continúa con el gobierno Reagan, que fue el verdadero hacedor del cambio de rumbo de la guerra en favor de Marruecos, y se señala cómo su diplomacia se mostró abiertamente partidaria a favor de Hasán II, apoyándole para que ganara la guerra. Los republicanos consideraron que era la alternativa más segura para su estrategia de dominación en el Norte de Africa. En la tercera parte se hace una cuantificación de las diferentes formas de apoyo que llevó a cabo el gobierno republicano de EE UU.

El trabajo se apoya en fuentes primarias norteamericanas y en bibliografía especializada. Por medio de ellas hemos podido explicar el interés de EE UU en el conflicto. Los documentos e informes de distinto nivel elaborados por la CIA o el Departamento de Estado, así como los fondos de James Baker depositados en la Biblioteca Reagan y en la Oficina de Seguridad Nacional, nos dan pruebas de todo lo relatado en este trabajo.

\section{Un largo conflicto no resuelto}

La continuidad del conflicto hasta nuestros días pone de manifiesto el fracaso de la estrategia norteamericana y el error parcial de los análisis de la época de Reagan. La guerra nunca fue una ramificación de la confrontación Este/Oeste, como 
reiteradamente argumentaban Hasán II y los halcones de Washington. La guerra en el Sáhara se debió a los afanes expansionistas de Marruecos. El apoyo norteamericano está influenciado por el deseo de reforzar a un buen aliado de Israel en el mundo árabe. La reanudación de la guerra en 2020 lo refleja claramente. Por un lado, el comienzo de las hostilidades en Guerguerat el 14 de noviembre de dicho año, y por otro, el reconocimiento que hizo Trump de la soberanía de Marruecos sobre el Sáhara Occidental, a cambio de que este país estableciera relaciones diplomáticas plenas con Israel, así lo demuestran. La zona ha sufrido desde entonces un aumento de la tensión militar y diplomática ${ }^{2}$.

El proceso de paz no llegó a buen fin a pesar de que la posición de fuerza marroquí se había fortalecido tras el importante apoyo norteamericano recibido bajo los gobiernos republicanos de los años ochenta. A finales de la década posterior se puso en marcha una estrategia encaminada a integrar a la población de los territorios ocupados, intentando marginar a los actores del movimiento de liberación con base en Tinduf. El Polisario logró mantenerse unido, aunque en horas bajas, sin embargo, no fue eliminado de la escena. El rechazo al Plan Baker I y II dejó el conflicto sin intermediarios internacionales que pudieran proponer una salida a la crisis. Internacionalmente se promocionó la idea del plan de autonomía. España jugó a ser altavoz de esa propuesta, dado que era una alternativa que le permitía no asumir sus responsabilidades de descolonización, salvar el problema y, a la vez, continuar con las buenas relaciones con Marruecos.

No entraba en los planes del Frente Polisario tamaña claudicación. Las protestas en las zonas ocupadas, principalmente en sus ciudades, desembocó en 2010 en el campamento de Gdeim Izik, dando con ello el pistoletazo de salida a lo que se denominó la Primavera Árabe. Veinticinco mil saharauis denunciaban las condiciones políticas, económicas y sociales a las que eran sometidos por el régimen de ocupación, a pesar de las grandes inversiones que Rabat había acometido en el Sáhara Occidental con un triple objetivo. Primero, incorporar al consenso promarroquí a los saharauis de esos territorios. Segundo, separarlos de los saharauis de Tinduf y del exilio. Y, tercero, quebrar la voluntad de constituir una república independiente. Hay que señalar que los beneficiarios principales de esas grandes inversiones fueron los colonos marroquíes.

El campamento fue rodeado por los militares y los paramilitares (colonos) marroquíes y, sobre él, se desató una dura represión que causó decenas de heridos, la muerte de al menos tres personas, una menor de edad, y la detención de centenares de saharauis. Desde entonces la persecución a los saharauis en las ciudades ocupadas ha sido constante ${ }^{3}$.

\section{La iniciativa relativamente moderada del gobierno Carter}

La participación norteamericana en la guerra del Sáhara Occidental en la década de los ochenta fue determinante para cambiar el rumbo de la contienda. Hasta la plena

\footnotetext{
Ver https://www.elsaltodiario.com/sahara-occidental/reconocimiento-trump-soberania-marroqui-sobre-saharaoccidental-

3 Ver el documental Gdeim Izik - El campamento de la Resistencia Saharaui en https://www.youtube.com/watch?v=KT480sFZsbY. Ver también Generación Saharaui de la Amistad (2012).
} 
implicación norteamericana, el Frente Polisario había mantenido una ventaja militar y estratégica muy clara sobre las fuerzas militares del reino alauita.

Durante el segundo quinquenio de los años setenta, el Frente Polisario fue ganando la guerra de manera clara. La intervención de la administración de Reagan a partir de 1981 cambió radicalmente el sentido de la contienda. Los norteamericanos financiaron y asesoraron a la monarquía de Marruecos en un momento cumbre de la fase final de la guerra fría. El diseño de la estrategia defensiva de los muros (Fuente Cobo y Mariño Menéndez, 2006; SSI, 2013), la utilización de la aviación y armamento sofisticado que los norteamericanos aportaron a Marruecos terminó expulsando al Frente Polisario del $85 \%$ del territorio que hasta entonces estaba bajo su control. El Polisario se tuvo que refugiar de manera permanente en los campos de Tinduf perdiendo la iniciativa en la guerra. La construcción de los muros defensivos terminó siendo una estrategia solvente desde el punto de vista militar para contener los ataques saharauis sobre las fuerzas marroquíes.

La preocupación norteamericana estaba centrada en mantener las alianzas conseguidas en el norte de África. Su apuesta por Marruecos estaba en primer lugar justificada por el temor al régimen de Libia, más que al rival estratégico principal que era Argelia. Con este país existían canales de entendimiento y sólidas relaciones comerciales.

A finales de los setenta Marruecos había perdido la iniciativa en la guerra. El régimen no era estable, y la crisis económica y el descontento de la población eran evidentes. La causa del Sáhara se había convertido en un elemento de cohesión del Majzen. La estructura del Estado dependía de esa oligarquía tradicional que controlaba todos los canales del poder marroquí. Además, la guerra del Sáhara alentaba el nacionalismo de las masas y ayudaba a reforzar la figura del rey, quien tuvo que afrontar dos importantes intentos de golpe de estado en el pasado (Laroui, 2007; Gourdon, 1972).

Tras la retirada mauritana de la guerra en agosto de 1979 (Ould Daddah, 2012), los saharauis concentraron todo su poder de fuego sobre la zona controlada por Marruecos. Desde la retaguardia en Tinduf los guerrilleros del desierto supieron explotar su conocimiento del terreno y asestaron duros golpes a los militares marroquíes. La estrategia del Polisario se asentaba más que en un triunfo militar incontestable, en hacer que la aventura de la guerra fuese demasiado onerosa en vidas humanas y dinero para Hasán II.

A finales de los setenta los norteamericanos mantenían una posición de apoyo a Marruecos, pero no era tan importante como luego lo fue con los gobiernos republicanos de la década posterior. EE UU calibraba quiénes eran los polisarios, y obsesionados con la doctrina de suma cero de la Guerra Fría se ocuparon de entender cuáles eran sus posiciones en la arena internacional.

En un informe de investigación sobre el terreno realizado por la CIA se enmarcaba la identidad del Frente Polisario entre los países progresistas del Tercer Mundo, aunque señalaba que los polisarios estarían interesados en mantener buenas relaciones con EE UU y valoraban positivamente la actitud americana en su postura ante el conflicto, no reconociendo los derechos de Marruecos sobre el territorio ocupado del Sáhara Occidental, lo cual les abría una esperanza sobre una actitud más comprometida de EE UU en el establecimiento de la paz y el reconocimiento del derecho a la autodeterminación. 
Aunque reconocen la posición no alineada del Frente Polisario, los reflejos del anticomunismo en la política exterior estadounidense se ven plasmados en el informe cuando advierten que puede haber esfuerzos de la URSS y de Cuba para ampliar su influencia en la zona, aunque, advierten, manteniendo sumo cuidado con no dañar las buenas relaciones económicas y diplomáticas que la URSS sostiene con Marrue$\cos ^{4}$. No obstante, perdura la desconfianza sobre las intenciones de la URSS y sobre la posibilidad de que aprovechara la creación de un nuevo estado para aumentar su influencia. En dicho informe se reconoce que "Argelia no tiene reclamaciones sobre el Sahara". Argelia con su apoyo a la causa saharaui "mantiene su cuidada imagen anticolonial" y a la vez se esfuerza por mantener una posición de fuerza clara ante las demandas irredentistas de la monarquía alauí, dado que Marruecos también reclama territorios que pertenecen a la república de Argelia.

La obsesión con la doctrina de suma cero en la política exterior norteamericana marcó sus posiciones. Aunque no había evidencias de la implicación de la URSS en el conflicto saharaui, los informes de inteligencia advertían sobre la posibilidad de penetración comunista de cualquiera de las maneras. La URSS llevaba a cabo, según esta visión, esfuerzos para penetrar áreas del Tercer Mundo e influir en acontecimientos y organizaciones, apoyando a elementos no comunistas como había ocurrido en Argelia, Yemen o Angola. Pero en el caso del Sahara Occidental los soviéticos estaban empleando tácticas encubiertas para no estropear sus buenas relaciones comerciales con Marruecos ${ }^{5}$. En 1978, los intercambios comerciales entre Marruecos y la URSS ascendía hasta los nueve mil millones de dólares. Y la URSS era el principal proveedor de petróleo para el reino alauí. Las relaciones entre Marruecos y la URSS fueron principalmente económicas y culturales y los soviéticos tenían gran interés en el acceso a los fosfatos (Zoubir, 1987). El volumen total de los intercambios comerciales de la URSS con Marruecos era superior al que tenía con Argelia en 1980. En el computo porcentual global con los países árabes, los intercambios con Argelia representaban el 6\%, mientras que con Marruecos eran del 8\%. Sin embargo, tenía un nivel de intercambio mayor con Libia, con el $18 \%$ del volumen total ${ }^{6}$. La relación de los soviéticos con la causa saharaui fue muy ambigua, y siempre prefirió favorecer sus relaciones económicas con Marruecos, a pesar de las sospechas que los norteamericanos tenían al respecto.

Los movimientos diplomáticos del Polisario fueron a la par que los avances en el terreno militar, y el reconocimiento de la RASD siguió su curso de manera imparable, lo que motivó que los aliados de Marruecos actuaran para presionar en las instancias en donde fuera necesario. En 1982 la Organización para la Unidad Africana se vio sometida a tensiones tras aceptar como miembro a la RASD. La respuesta de Marruecos fue abandonar dicha organización. Pero en los años precedentes a la admisión, y cuando la fortaleza militar del Polisario había adquirido su punto álgido, un buen aliado neocolonial de Francia, como fue Senghor, a la sazón presidente de Senegal, amenazaba también con su marcha de la OUA si los saharauis eran admitidos en la misma ${ }^{7}$. Senegal mantuvo una actitud beligerante contra las posiciones de

4 CIA-RDP80T00942A000800130001-2. The Western Sahara Conflict. Morocco's Millstone (s). An Intelligence Assessment. Research for this report was completed on 23 March 1979.

5 CIA-RDP84B00049R001102650002-0. National Foreign Assessment Center 31 July 1981. Soviet penetration the Third World.

6 Ver http://www.eurosur.org/ai/afric14f.htm

7 CIA-RDP85T00287R000101520001-4. West Africa Background Papers for the President. 10 July 1980. 
Libia y Argelia en el asunto del Sáhara Occidental. Incluso el presidente Senghor se había apresurado a defender, de hecho, la ocupación de Marruecos y Mauritania, e invitaba a esos dos países a llevar a cabo una explotación conjunta de los recursos naturales del territorio, en consonancia con lo que también pedía Arabia Saudita. En un alarde de afrancesamiento extremo, muy propio del presidente senegalés: "A partir de 1978 Senegal tomaría parte beligerante en el conflicto puesto que serviría de base a las fuerzas francesas para combatir al pueblo saharaui" (Diego Aguirre, 1991, p.179).

A pesar de estas posiciones de algunos regímenes, como el senegalés, la RASD fue creciendo en apoyos diplomáticos hasta su inserción en la OUA en febrero de 1982, con el apoyo de 26 países miembros. Marruecos abandonaría dicha organización en 1984.

La preocupación de EE UU a comienzo de los años ochenta era la debilidad del régimen marroquí. En el mes de junio, una violenta represión cayó sobre las masas que protestaban en Casablanca, desesperadas por la grave crisis económica que atravesaba el país, agravada por la medida gubernamental de subir un $15 \%$ los precios de los productos básicos. La Confederación Democrática del Trabajo había convocado una jornada de huelga el sábado 20 de junio de 1981 para mostrar su desacuerdo con esas medidas, y con el deterioro general de la situación empeorada por la sequía de aquel año, la escasez de cereales y los gastos de guerra en el conflicto del Sáhara. En la ciudad de Casablanca, la represión del movimiento huelguístico se saldó con centenares de muertos, entre 600 y 1.000 se estimaron, millares heridos de bala y entre 6.000 y 8.000 detenidos (Perrault, 1991). Las fuerzas de la oposición denunciaron la brutalidad empleada, y todo ello transmitía la sensación, junto con los dos intentos de golpes de estado sufridos en la década anterior, de que la monarquía de Hasán II pasaba por momentos muy delicados. Las cifras que se manejaban apuntaban a un déficit presupuestario que alcanzaba los 8.000 millones de dirhams, mientras el $40 \%$ del presupuesto estatal se dedicaba a la guerra en el Sáhara.

A finales de 1981, en un informe de naturaleza secreta se decía:

La economía está sufriendo una ralentización provocada por el programa de austeridad impuesto en 1978 a raíz de años de gastos excesivos y del colapso del mercado de fosfatos. El alto gasto en defensa y una deuda externa considerable agravan el problema ${ }^{8}$.

El análisis remarcaba la relación existente entre el deterioro de la situación económica y la guerra del Sáhara, pero señalaba que el Rey no podía abandonar la causa saharaui porque eso debilitaría su posición en el interior de Marruecos tras años de propaganda sobre la marroquización del Sáhara Occidental.

La ofensiva militar del Polisario del mes de octubre de 1981 había dejado en evidencia al ejército marroquí, que se vio sorprendido por la audacia y el poder de fuego de los saharauis. Operaciones de los años anteriores también dejaron en mal estado a las fuerzas militares marroquíes. De manera particular la incursión hasta Tan Tan con una columna motorizada de 1.200 guerrilleros que entró hasta la ciudad, tomándola y partiendo con un buen número de prisioneros. Pero en octubre de 1981 la demostración de fuerza polisaria fue aún mayor. Por primera vez hicieron uso de

8 CIA-RDP84B00049R001403550020-7. Morocco: Increasing Domestic Difficulties. 
misiles antiaéreos SAM-6 y SAM-9, además de despliegues de tanques T-54 y T-55. La batalla de Guelta Zemmur fue una verdadera sorpresa para los analistas y, por supuesto, para los militares marroquíes. El derribo de los aviones de combate y de seguimiento, así como la captura o destrucción de una ingente cantidad de material concluyó con la destrucción total del IV Regimiento del ejército, que hasta ese momento estaba compuesto por 3.500 tropas entre solados y oficiales. Marruecos acusó directamente a Libia, Cuba, la RDA y Mauritania de haber estado implicados en la preparación y el ataque de los días 13 y 14 de octubre?

Los norteamericanos sospechaban que toda esa serie de acontecimientos podría quebrar la unidad de la dirección militar dentro de las fuerzas armadas de Marruecos. Los estadounidenses comenzaron a percibir divisiones entre los oficiales superiores y los oficiales intermedios acerca de cómo debía afrontarse la guerra. La propia figura del rey no pasaba por sus mejores momentos dentro del ejército: "Fuentes de la Embajada de los EE UU informaron que hay un resentimiento creciente hacia el gobierno y el propio Rey incluso en el campo, donde su posición siempre ha sido fuerte" $"$.

Durante los primeros años del gobierno Carter, las ayudas a Marruecos se contuvieron con la intención de poder mejorar las relaciones con Argelia, aunque ello no significó que los norteamericanos no apoyasen el esfuerzo de guerra de Marruecos, igual que estaba haciendo Francia. Tras la retirada de Mauritania de la guerra, Carter aumentó el apoyo a Marruecos surtiéndolo de helicópteros y aviones, a la par que de un sistema "de detección electrónica por un valor de 200 millones de dólares, que tendría por objeto descubrir la presencia de los atacantes saharauis a lo largo de los muros que Marruecos proyectaba y empezaba a construir a lo largo del Sáhara" (Diego Aguirre, 1991, p.213; Feliu, 2013). La caída del Sha en Irán en 1979 fue un factor que tuvo en cuenta EE UU para reforzar los lazos con Marruecos. Los informes de los servicios secretos no auguraban un futuro prometedor a la monarquía alauita, a menos que estuviese sostenida por los propios norteamericanos. De esta manera, los demócratas anticipan tímidamente el cambio de posición del gobierno una vez llegaran los republicanos, los cuales iban a invertir de manera generosa en el sostén del régimen en Marruecos, y a ser una pieza clave en el cambio de signo de la guerra en el Sáhara.

\section{Las justificaciones estratégicas del gobierno de Reagan}

El 20 de enero de 1981 asumió la presidencia el republicano Reagan, y con él la guerra comenzó a tomar un rumbo favorable para Marruecos. EE UU no quería ver un nuevo Irán, y estaba decidido a inclinar la balanza de la guerra en favor de Hasán II. El panorama que contemplaba le preocupaba porque la crisis económica y el descontento seguían en aumento. Por eso, EE UU respaldó tanto la guerra en el Sáhara como la política represiva en el interior. Ello les daba garantías de continuidad de la monarquía alauí. Con la llegada de Reagan a la Casa Blanca EE UU consideró que la represión de las fuerzas opositoras era un elemento de estabilidad necesario, y aplaudió la habilidad de Hasán II:

\footnotetext{
9 Ver https://www.ecsaharaui.com/2020/11/la-batalla-de-guelta-zemmur-13-y-14-de.html

10 CIA-RDP84B00049R001403550020-7. Morocco: Increasing Domestic Difficulties.
} 
El Rey ha manipulado, cooptado o reprimido prácticamente toda la oposición al régimen. La Unión Socialista de Fuerzas Populares, el único partido creíble de oposición en Marruecos ha visto restringidas severamente sus actividades. Su Secretario General y otros miembros de la dirección fueron arrestados en septiembre y permanecieron en prisión hasta marzo ${ }^{11}$.

También la represión alcanzó al movimiento estudiantil, a los islamistas y al sindicato CGT responsable de las movilizaciones de la clase trabajadora que había sido tan duramente castigada. El sindicato estaba moribundo. Toda su dirigencia en prisión, de tal manera que Hasán II se encontraba con las manos libres para amordazar el descontento popular. La represión se empleó de manera dura contra los dirigentes seculares, pero fue muy blanda con los dirigentes islámicos, de tal manera que entre ellos no hubo presos y pudieron seguir realizando sus actividades proselitistas. Con esas condiciones, el rey tenía las manos libres para afrontar la ofensiva de la guerra en el Sáhara, sin tener que atender a problemas de desórdenes internos.

Hasán II pudo mantener el control del sistema político utilizando las tácticas de dividir a la oposición, otorgando beneficios de libertad política o restringiéndolas para mantenerse como árbitro permanente de la situación, según nos advierte un informe de los servicios secretos estadounidenses destinado a informar al resto de agencias de seguridad de su país. En el memorándum se estima que con ese juego de mantener dividida a la oposición, junto con la fidelidad del aparato de seguridad, siempre presto a reprimir las manifestaciones de descontento, y junto a ello la fidelidad del ejército, se garantizaba la continuidad del régimen. Además de la guerra en el Sáhara, el país tenía que afrontar el rápido crecimiento demográfico y un alto porcentaje de población joven en un ambiente de miseria generalizada, aumento de la inflación y la deuda externa, que detraía recursos de las necesarias inversiones sociales y de la economía productiva. Ante esa situación "si el sistema actual no satisface las crecientes aspiraciones populares y sociales, las presiones probablemente generarán demandas de cambios políticos importantes" "12, que no serían del agrado de los norteamericanos.

La situación en el Sáhara era un elemento de desestabilización interna y de tensiones con los otros países del Magreb. Marruecos veía en Argelia, Libia y la URSS los principales enemigos de su régimen, y los puntos de apoyo del Frente Polisario. Por eso Hasán II fue partidario de situarse en la línea de la política exterior de EE UU. Hasta 1982, los americanos pensaban que si no había una pronta solución del conflicto, bien por la vía de la victoria militar rápida o bien por medio de una negociación que llevase a la paz, la única manera de mantener la monarquía era gracias a las ayudas que recibía de Arabia Saudita, aliado que soportaba el grueso de los gastos de la guerra.

Los norteamericanos deseaban que Marruecos consolidara su posición, pero una ayuda muy evidente y una toma de partido sin medias tintas a su favor podría perjudicar la profundización de sus relaciones económicas con Argelia, de la que estaba interesada en adquirir gas y petróleo. Los argelinos deseaban estrechar sus relaciones

11 CIA-RDP83B00232R000100100005-3. Morocco: Prospects for kay opposition groups. An Intelligence Memorandum. Secret, May 1982.

12 CIA-RDP85T00176R001500120025-1. Prospects for Morocco. Secret. 11 May 1982. 
con EE UU, pero no a cambio de abandonar su apoyo a la causa saharaui y de perder su rol principal como país líder de los países no alineados (Prashad, 2012).

Para Estados Unidos, la posición geoestratégica de Marruecos era un valor muy estimable, dado que era la puerta de entrada al Mediterráneo, una zona muy sensible durante la Guerra Fría, además de ser frontera con uno de los países más relevantes del tercermundismo y socio comercial y militar de la URSS. Marruecos garantizaba el uso de sus puertos tanto en el Mediterráneo como en el Atlántico, y también servía para reforzar el flanco sur de la OTAN, manteniendo protegida a España y Portugal si se desataba un conflicto con el Pacto de Varsovia. Por todas esas razones EE UU quería en Marruecos un aliado firme, porque además tenía "relaciones sólidas con África del Norte, Medio Oriente y África subsahariana que son importantes para los Estados Unidos" $"$.

El mapa que hacen los norteamericanos sobre los amigos y enemigos en el tablero saharaui les permite situar su propia posición. Los sectores mayoritarios se inscriben ideológicamente en el marco del nacionalismo árabe. En el frente interno clasifican tres corrientes dentro del Polisario, un grupo pro-argelino, otro pro-libio y un núcleo más reducido de inspiración marxista. En el campo estratégico, a la RASD la apoyaban Cuba, Irán, Libia y Argelia, mientras que Arabia Saudita e Irak apoyaban a Marruecos. En el informe citado se apunta que hay un papel complementario entre Argelia y Libia en su apoyo al Polisario. Por Argelia pasa todo el armamento que llega a los guerrilleros saharauis, el entrenamiento, la logística, avituallamiento y, sobre todo, los campos de refugiados de Tinduf. Por su lado, Libia aporta el $80 \%$ de la ayuda militar y financiera.

Tras el ataque de Guelta Zemmur, Marruecos comenzó un repliegue de sus guarniciones más alejadas, y se concentró de manera decidida en la construcción de los muros de separación. La estrategia de los muros se iba a mostrar acertada para Marruecos porque alejaba las posibilidades de ataques y de incursiones polisarias, a la vez que garantizaba el control de los territorios más rentables de la antigua colonia española.

En el periodo más crítico de la guerra para Marruecos, que tuvo lugar a principios de los años ochenta, la posición española fue clave. Aunque los socialistas habían llegado al poder a finales de 1982, y tenían un discurso de simpatía y cercanía hacia los saharauis, la potencia atlantista tenía claro que España debía de elegir bando en esa guerra: "Los socialistas están preocupados por la vulnerabilidad de sus enclaves norteafricanos y, en menor medida, de las Islas Canarias, y que puedan ser tomados por Marruecos" 14 . Cuando el ministro de Asuntos Exterior, Fernando Morán, fue a entrevistarse con Hasán II en diciembre de 1982 (Marquina Barrio, 1983) para preparar la vista del presidente González de marzo de 1983, seguramente ya iba con el encargo de transmitir al rey de Marruecos la posición del gobierno español: "Los socialistas pueden intentar mantener la buena voluntad de todas las partes promoviendo una solución negociada de la disputa del Sáhara Occidental (...) sin embargo, los socialistas se verán obligados a elegir bando y optarán por Marruecos"15. Esta posición garantizaba mayor tranquilidad al flanco sur de la OTAN.

Ibid.

14 CIA-RDP84S00555R000100050002-6. Directorate of Intelligence. Spain: Socialist Foreign Policy. January 1983.

15 Ibid. 
Los norteamericanos habían comprendido que la posición española iba a estar enmarcada en la misma línea de actuación de los gobiernos anteriores, desde los del último franquismo a los de la UCD. El nuevo gobierno socialista mantendría el criterio de atemperar las reivindicaciones marroquíes sobre los enclaves africanos en impedir la creación de un estado nacionalista aliado de Argelia al sur de Marruecos y frente a Canarias. El PSOE fue de la misma opinión que el Alto Estado Mayor del ejército de 1975, "en su óptica estratégica un Sáhara independiente en la órbita argelina y libia es un peligro para Canarias y un hueco en el sistema defensivo occidental en el Atlántico norte" (Diego Aguirre, 1991, p.100). Los jefes militares españoles de 1975 querían que Marruecos se anexionase al Sáhara para evitar ese peligro de extensión del problema hacia las Islas Canarias, y se esperaba lograr de Marruecos "el olvido indefinido de las reivindicaciones sobre Ceuta y Melilla" (ibidem.).

El auge del islamismo en el mundo árabe cobró una dimensión política enorme tras el triunfo de la revolución iraní. El influjo que generó el chiismo político alcanzó a los lugares en donde esa secta era numéricamente importante, en países tales como Líbano e Irak, aunque no era menos de temer el fundamentalismo islámico en los países de mayoría sunita. Y Marruecos es un país de amplia mayoría sunita. Los norteamericanos, a pesar de que estratégicamente apostaban por reforzar la monarquía alauí en detrimento del nacionalismo saharaui, observaban y vigilaban con atención la evolución del islamismo en el seno de la población marroquí. Esperaban que, en cualquier caso, Hasán II tuviese la suficiente ascendencia sobre los fieles y súbditos como para mantener controlados a los creyentes exaltados.

A comienzos de 1983, la Oficina de Análisis del Cercano Oriente y Asia Meridional de la CIA elaboró un documento que coordinó el Consejo Nacional de Inteligencia y la Dirección de Operaciones, bajo la supervisión del Jefe de la División Árabe-Israelí, en el que se hizo un pormenorizado estudio de la evolución de las corrientes islamistas en Marruecos. El informe llevó por título "Marruecos: islam y política".

En ese documento se advertía que los problemas de orden económico y social por los que atravesaba el país, y el influjo de la revolución islámica en Irán, podrían amenazar el orden establecido, aunque también se subrayaba que hasta ese momento el islamismo político era una vía minoritaria, y no ponía en peligro la monarquía de Hasán II. La paradoja con la que se encontraban los norteamericanos era que pensaban que sería urgente apoyar y garantizar la continuidad de la monarquía, pero su apoyo no debía ser muy visible para no enardecer a los críticos islamistas, que denostaban la injerencia occidental y, en particular, estadounidense, en los asuntos internos de Marruecos:

En las principales ciudades donde el estrés de la modernización y la situación de las recientes dificultades económicas se han sentido de manera más aguda, algunos extremistas buscan hacer borrón y cuenta nueva y establecer un "verdadero" Estado islámico a través de la violencia. El sentimiento revivalista parece tener cierto atractivo para la gran cantidad de jóvenes del país, y es posible que graviten en mayor número hacia el extremismo islámico si quedan significativamente insatisfechos con el manejo gubernamental en la política interior y exterior ${ }^{16}$.

16 CIA-RDP84S00556R000100070002-7. Morocco: Islam and Politics. February, 1983. 
No obstante, se piensa que el carácter conservador de la población marroquí, su condición profundamente religiosa, en la que el rey es la principal figura civil y religiosa del país, contiene de momento a los extremistas. Para los marroquíes atacar al rey es sinónimo de atacar a la religión, y esa circunstancia se convierte en un muro de sujeción que favorece la estabilidad y la continuidad de la monarquía. "No es

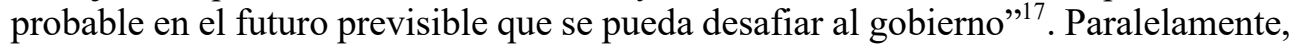
Hasán II, al objeto de contener el peligro fundamentalista, fomentó el renacimiento de hermandades musulmanas tradicionales, creó y patrocinó grupos religiosos afines al gobierno para así encauzar el aumento de la religiosidad percibida en los últimos años, sobre todo en el incremento de la asistencia a las mezquitas y el cumplimiento de los preceptos del islam, tal como el ramadán. De esta manera se pretende combatir los efectos y la influencia de la revolución iraní, sobre todo entre las grandes masas de jóvenes.

El hecho de que el descontento de los jóvenes se canalizara a través del islam se vio favorecido por la tremenda represión que vivieron los partidos de oposición laica en los años precedentes, y su incapacidad por ello para levantarse como alternativa creíble al gobierno. Hasán II reprimió a los socialistas y les cortó su actividad política, pero paralelamente dejó actuar a los grupos religiosos, sabiendo que para él sería más fácil controlar a esos grupos que a la oposición sindical y política de base socialista. Por supuesto, este punto de vista y esta práctica fue bien vista por los norteamericanos, para los que era preferible reforzar el tradicionalismo religioso que dejar que se desarrollara el nacionalismo laico y socialista (Amin, 2011; González del Miño, 2014).

La táctica de apoyarse en los islamistas para debilitar a los socialistas y a los nacionalistas se había puesto en práctica desde principio de los años cincuenta, y fue reforzada por la alianza estratégica entre Arabia Saudita y los EE UU para combatir la creciente influencia de Nasser sobre las masas árabes de todos los países:

La Doctrina Eisenhower estaba formulada como una estrategia con la que contener al comunismo en general, pero en el caso específico de Oriente Próximo y Medio, proponía favorecer a los sauditas y a otras fuerzas monárquicas (como el sha de Irán y los reyes de Jordania e Irak) como alternativa al nasserismo (Prashad, 2012, p.442).

Dicha doctrina se vio reforzada cuando los norteamericanos constataron la evolución y consolidación del proyecto nasserista como un modelo que exploraba elementos socialistas para la ordenación y el desarrollo de su economía, y que en el plano estratégico ampliaba y profundizaba sus relaciones con la URSS (Lacouture, 1972).

Hasta 1961, Marruecos, buscando mitigar su dependencia económica de sus exmetrópolis y de los EE UU, buscó ampliar sus relaciones con la URSS y el bloque oriental, pero después de ese año su viraje hacia el mundo occidental será definitivo y determinante. Aunque siguiese manteniendo relaciones económicas con los soviéticos, su apuesta de largo alcance sería definitivamente del lado pro-occidental. En el mundo árabe, Marruecos se sumó a la estrategia norteamericana de cerco al Egipto de Nasser y al nasserismo como alternativa política, jugando un papel destacado dentro de los países conservadores del Tercer Mundo y sus organizaciones, tratando 
de bloquear las opciones nacionalistas revolucionarias y antiimperialistas en beneficio de las monarquías tradicionalistas (Willis, 2014).

La habilidad que mostraba Hasán II para manipular los sentimientos chovinistas y religiosos del pueblo marroquí era celebrada con alegría por los EE UU y reforzaba la idea de que Hasán II era el hombre que necesitaban para mantener a Marruecos como un país aliado en el futuro:

Hassan moviliza el apoyo masivo mediante la manipulación de los valores religiosos y reafirmando los lazos directos entre él y su pueblo (se muestra como) líder de importantes ceremonias religiosas o lee el Corán en televisión desde el Palacio. Para la "Marcha Verde" en 1975, Hassan explotó el fuerte sentimiento popular de que el Sahara Occidental es históricamente parte de Marruecos. Movilizó un ejército de varios cientos de miles de civiles armados sólo con copias del Corán y la tradicionales banderas islámicas y nacionales, para consolidar su pretensión sobre el territorio ${ }^{18}$.

El Informe no menciona que, además, Francia y los EE UU facilitaron la Marcha Verde apoyándola diplomáticamente.

Por su parte, los grupos islamistas no controlados por el rey hacían proselitismo entre los pobres urbanos y rurales, reforzándoles la idea preexistente de que había mucha corrupción dentro del Palacio, lo cual podría profundizar la deslegitimación del propio rey, si éste no fuese capaz de atajar la crisis económica y social que azotaba al país (Wright, 1985).

El gobierno de Reagan, mucho más decidido a intervenir en favor de Marruecos, daba un giro a las políticas menos comprometidas de Carter, y apostaba por el rearme de sus aliados de manera más cuantiosa, y esto repercutió claramente en el conflicto del Sáhara Occidental en detrimento del Frente Polisario:

La administración Reagan rechazó la opinión de que los cambios en el sistema internacional durante los últimos veinticinco años habían limitado la capacidad de Estados Unidos para dar forma a los eventos regionales. Vio la serie de eventos globales desfavorables que ocurrieron durante la administración Carter como un fracaso a la hora de que los EE UU reafirmaran su poder (Wright, 1985, p.140).

Obviamente la revolución iraní estaba en la mente del presidente republicano.

En un documento que salió de la Casa Blanca en abril de 1985, y que llevaba la firma de Reagan, se establecieron las prioridades norteamericanas tras el acuerdo de Oujda entre Marruecos y Libia firmado en 1984 (Gibler, 2009: Zoubir y Hamadouche, 2013). El acercamiento de Hasán II con Gadafi no era en absoluto bien visto por el gobierno de Reagan. La política de aislamiento sobre Gadafi podía peligrar con esa deriva marroquí, y los norteamericanos le pidieron garantías personales a Hasán II de que su aventura no llegaría muy lejos. Por su parte, Hasán II buscaba con esa maniobra desactivar el apoyo que Libia prestaba al Frente Polisario.

Estados Unidos planteaba seguir manteniendo estrechas relaciones de cooperación militar y económica con Marruecos, aunque su diplomacia anunciaba que debía seguir trabajando con Marruecos y Argelia para buscar una solución al conflicto del 
Sáhara. La presión que mantenía activada los EE UU sobre Marruecos estaba encaminada a que se derogase el acuerdo alcanzado con Libia, y eso pasaba por hacer que la "cooperación con el Gobierno de Marruecos debe ser tal que haga que la unión sea menos aceptable para Gadafi" ${ }^{19}$, por lo que estimaban que era preciso llevar a término el Acuerdo de Seguridad General de Información Militar (GSOMIA) y mantener la cooperación económica Joint Economic (JEC), así como la comisión militar conjunta Joint Military (JMC). Por tanto, el apoyo a la monarquía alauita se mantendría, al pensar que el acuerdo de naturaleza económica estaría centrado sobre todo en el Tratado Bilateral de Inversiones y en el Acuerdo Bilateral de Turismo. Los estadounidenses optaban por afianzar su alianza con Marruecos sospechando que el acuerdo de Hasán II con los libios no tendría mucho recorrido como, efectivamente, quedó patente en el año 1986 cuando fue anulado de manera definitiva. La política norteamericana en el norte de África estaba asentada sobre la relación principal con Marruecos, en menor medida con Túnez, el incremento de las relaciones económicas y culturales con Argelia, aunque sabiendo que los argelinos mantenían una posición independiente y comprometida, en todo caso, con la causa de los saharauis, y en el aislamiento absoluto sobre la Libia de Gadafi:

Se establecerá un grupo interinstitucional presidido por el NSC para revisar nuestra estrategia hacia Libia, y preparar las opciones políticas para contener las actividades subversivas de Gadafi. A la espera de la revisión de la estrategia, seguir estrechando lazos con los vecinos de Gadafi mientras calibramos nuestra retórica para avanzar en nuestras metas sin elevar el estatus de Gadafi en la arena internacional. Si bien se mantienen las sanciones económicas vigentes contra Gadafi, el comité interinstitucional presidido por el Departamento de Estado revisará posibilidades de aumentar dicha presión ${ }^{20}$.

Las líneas de actuación de la política norteamericana para el norte de África habían sido establecidas desde la Oficina de Seguridad Nacional en septiembre de 1984, es decir, un mes después del acuerdo entre Marruecos y Libia, y en ella se respondía a la pregunta: " $¿ Q$ Qué puede hacer Estados Unidos para ayudar a frenar a Libia, la agresión y el terrorismo en el norte de África y facilitar la resolución del conflicto del Sáhara Occidental?"21.

A la luz de los hechos, y del apoyo militar y financiero a Marruecos sostenido por la administración de Reagan, la respuesta a dicha pregunta tuvo un carácter meramente retórico, y ahondó en la vaga idea de apoyo a las negociaciones destinadas a resolver la guerra en el Sáhara, sin llevar a cabo una acción decidida. Aunque sí se detectan las bases de lo que posteriormente se conoció como el plan Baker, al recoger la propuesta siguiente:

La larga lucha entre Marruecos y el Polisario por el control del Sáhara Occidental sigue sin resolverse. Nosotros apoyamos los esfuerzos para que las partes contendientes negocien poner fin al conflicto y respaldar las resoluciones de las Cumbres de la OUA de Nairobi de 1981 y 1982 que especifican que la solución al conflicto

\footnotetext{
NARA, National Archives Identifier 6879763.1985

Ibid.

NARA, Library Reagan Collection: Baker, James A. : Files Folder Title: National Security Office (1) Box 9.
} 
debe incluir un alto el fuego anterior a un referéndum como una expresión de autodeterminación ${ }^{22}$.

Luego, en la práctica, el Plan Baker I, en el año 2000, quedó reducido a una propuesta de autonomía que los saharauis no estaban dispuestos a aceptar y que nunca se tomó en consideración en el Consejo de Seguridad de la ONU. El plan Baker II preveía un gobierno de transición de cinco años y un posterior referéndum de autodeterminación, se aprobó por el Consejo de Seguridad de la ONU en 2003 pero fue rechazado por Marruecos (Fernández Molina, 2013). Las otras ideas señaladas más arriba fueron en el sentido de fortalecer las relaciones económicas con Marruecos y Túnez, así como en mejorar las relaciones con Argelia.

La firma de los acuerdos entre Marruecos y EE UU tras la visita de Hasán II a la capital norteamericana en 1982 fue el inicio de una creciente ayuda militar americana a cambio de que los estadounidenses tuviesen acceso ilimitado a los puertos y aeropuertos en Marruecos. Fruto de esos acuerdos se estableció la Comisión Militar Conjunta, y Rabat comenzó a recibir los aviones de última tecnología, asesoramiento militar, ingenieros para levantar los muros, sistemas de radares y un largo etcétera de herramientas para poder darle un vuelco a la suerte de la guerra. Los créditos a la economía marroquí fueron millonarios.

El acuerdo entre Hasán II y Gadafi fue una maniobra dilatoria puesta en práctica por el monarca para cortocircuitar la ayuda del líder libio al Polisario, puesto que Gadafi se había convertido en un respaldo fundamental para la estrategia militar del Frente Polisario: "El rey Hasán inició la unión porque quería garantías de que Gadafi acataría un acuerdo para restringir el apoyo libio al Polisario"23. Tras la recepción de la generosa ayuda de la administración Reagan, y cuando la suerte de la guerra ya estaba a su favor, Hasán II rompe el acuerdo con Gadafi, para satisfacción de los estadounidenses: "Marruecos está ganando la guerra y probablemente esté menos preocupado por la reanudación del apoyo libio a las guerrillas" ${ }^{24}$. La medida pretendía acercar Marruecos a EE UU: "El rey esperaba que EE UU lo recompensara con ayuda económica y militar (y) allanara el camino para ampliar los créditos financieros de los gobiernos occidentales (a la vez) que obtener sofisticado equipo militar"25.

A pesar del respaldo recibido de los EE UU, Hasán II no tenía posibilidades de ganar militarmente la guerra, y a finales de 1986, si bien la contienda se decantaba del lado marroquí, nadie se hacía ilusiones de que habría un pronto final. Ciertamente, la estrategia de los muros había logrado reducir los golpes de la guerrilla del Polisario, pero no había logrado desmoralizarlos ni acabar con ellos de manera definitiva. El balance de tropas en la región del Sáhara era abrumadoramente favorable a Marruecos, según las estimaciones de la inteligencia americana que cifraba en 80.000 tropas marroquíes frente a 3.000 guerrilleros polisarios. El respaldo de Argelia al sostén de la guerra era determinante para que la RASD pudiese continuar resistiendo. Además, si era cierto que Marruecos dominaba militarmente, no era menos cierto que la posición de Argelia y la RASD había ganado mucho terreno en el mundo diplomático, y en especial entre los países del Tercer Mundo.

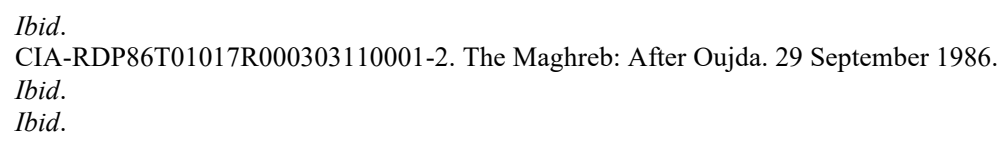


Diplomáticamente, Rabat no ha logrado el mismo éxito. Argel ha utilizado su sólida posición en el Movimiento de No Alineados con desembolso generoso de ayudas en África para conseguir apoyo internacional para el Polisario. Sesenta y cinco países, incluida India, Yugoslavia y Nigeria, reconocen al gobierno del Polisario en la República Árabe Democrática del Sahara (RADS). El músculo diplomático de Argelia ha producido fuertes apoyos por su posición en Naciones Unidas, y condujo a la retirada de Marruecos de la Organización de la Unidad Africana (OUA), tras el reconocimiento de la OUA a la RASD en $1984^{26}$.

Pero Argelia no podía imponer una solución al conflicto. Éste solo podía, y puede, venir de una implicación norteamericana que desee una solución justa en los términos establecidos en ONU y no era el caso. Si bien EE UU se mantenía en el terreno diplomático defendiendo las resoluciones de la ONU y de la OUA, en la práctica decantaba la guerra del lado marroquí, "simplemente apoyando al ejército marroquí" (Harvey, 1988). Estados Unidos se mostraba partidario de que se respetasen las fronteras de la era colonial, y públicamente así lo reafirmaba, por miedo a que en otros lugares se tomase el ejemplo de Marruecos y nuevos conflictos de reclamación de territorios comenzaran a surgir en otros escenarios poscoloniales. EE UU no apoyaba públicamente la anexión marroquí para evitar daños a sus relaciones con multitud de países del Tercer Mundo, incluida Argelia, y sabía que el apoyo argelino al Polisario era una cuestión fundamental para Argel. Pero también era consciente de que Argelia no llevaría el enfrentamiento con Marruecos a casus belli por el asunto del Sáhara, con lo cual, de hecho, su apoyo a Marruecos continuaría consolidando los intereses comunes entre ambos países.

\section{El apoyo material}

La ayuda material que recibe Marruecos no es solamente la que procede de EE UU, siendo ésta la determinante (Hodges, 1984). También Francia y Arabia Saudita son grandes soportes de Hasán II. El monarca es considerado un hábil político con capacidad para inventar problemas donde no los hay, para así ocultar los problemas en donde efectivamente sí los hay. Esto parecer ser la interpretación que hacían los servicios secretos norteamericanos cuando no dudaban en señalar que la Marcha Verde y la ocupación del Sáhara se llevaron a cabo "en parte para desviar la atención de los problemas internos de su país" $"$. Pero lo cierto es que su política expansionista tuvo el apoyo material de varios países poderosos y ricos. Con Arabia Saudita, a su vez aliado fundamental de EE UU en Oriente Medio, Marruecos compartió información de los servicios de inteligencia y desplazó a miles de militares para ser entrenados allí. También en Emiratos Árabes Unidos. Las cifras en millones de dólares recibidas por Marruecos de la monarquía petrolera son mareantes. En el periodo 1980-85 alcanzó la cifra de los tres mil millones de dólares, más setecientos millones en préstamos adicionales, y recibió el regalo de dos millones de toneladas métricas de

\footnotetext{
26 CIA-RDP88T00096R000600720010-7. Western Sahara: Scenarios for a Diplomatic Solution. April 1987.

27 CIA-RDP89S01450R000300310001-0. Morocco: Foreign Policy Dilemmas. May 1988.
} 
petróleo solo en $1985^{28}$. También recibió ayuda de Emiratos Árabes y de Kuwait trenzando así una poderosa alianza con las monarquías absolutas y sunitas del Golfo Pérsico. Así mismo, Marruecos mantuvo buenas relaciones con Israel, país del que también recibió asesoramiento militar y de inteligencia. Desde 1960, Hasán II entró en contacto con Israel, y en particular con sus servicios secretos, para que ayudaran a crear los servicios de información del reino. En el transcurso de los años posteriores, las colaboraciones fueron estrechas y muy importantes en momentos de crisis, bien de la monarquía alauita, o del régimen sionista de Israel (Diouri, 1992), y, además, "Egipto, Irán bajo el Sha, Jordania, Libia, Irak, Sudáfrica, Bélgica, Italia, España y Brasil suministraron armas a Marruecos durante la guerra con el Polisario" (SSI, 2013, p.45).

Todos los países citados son aliados estratégicos de EE UU, que se hacen cargo de costear la aventura marroquí en el Sáhara compartiendo los gastos con la potencia imperial central. A pesar de que se consideraba que durante el gobierno Carter los norteamericanos mantuvieron un perfil bajo de ayuda hacia Marruecos, lo cierto es que el montante ascendió desde 1974 hasta 1978 de los cuatro millones de dólares a los noventa y nueve millones, aunque se señalaba para entonces que EE UU prohibía el uso de la ayuda militar que le brindaba a Marruecos para usarla fuera de su territorio, tal y como se recogía en un acuerdo firmado entre ambos países en la temprana fecha de 1960 (Yousfi, 2014).

Con la llegada de Reagan al poder, la ayuda militar se disparó de manera creciente a lo largo de la década de los ochenta. Sólo una semana tras la asunción de la nueva presidencia se aprobó la venta de 108 carros de combate M-60, una partida de aviones C-130 con radar aerotransportado lateral, y aviones cisternas K-130 (ibid.). Y ése sólo fue el comienzo. Expertos en contrainsurgencia fueron enviados para asesorar a los militares marroquíes sobre el terreno. Nada de todo ello tenía que ver con las declaraciones diplomáticas que hacía el gobierno de los Estados Unidos.

Reagan ganó las elecciones y la noticia fue recibida con alegría por la monarquía alauí. Cuando el embajador norteamericano fue a mostrar sus credenciales a Palacio, le dijo a Hasán II que la nueva administración era la verdadera amiga de Marruecos, y que EE UU haría todo lo posible para ayudar a su amigo (Zunes, 1998). Bajo el gobierno Reagan, el aumento sustancial de la ayuda de guerra para Marruecos revirtió la marcha de la misma, y Hasán II pasó de controlar el 15\% del territorio a principio de la década a más del $90 \%$ a finales de los ochenta, "protegido por unos muros de puestos de defensa fortificados, diseñados y equipados por los estadounidenses y los franceses" (ibid.). La tecnología que se incorporó a los muros tenía capacidad para detectar movimientos hasta cerca de los cincuenta kilómetros de distancia, lo que favorecía sistemas de alerta temprana de las posiciones y los avances de las fuerzas guerrilleras.

El gobierno de EE UU a partir de ese momento no condicionaba la ayuda a los avances en el proceso de paz, ni tampoco iba a supeditar el uso de los artilugios militares a lo establecido en el acuerdo de asistencia firmado en 1960. Marruecos tenía vía libre para hacer uso de toda la nueva tecnología que recibía de su aliado principal. La lógica militarista del gobierno Reagan sostenía la tesis de que el aumento del potencial militar marroquí acercaría el conflicto a una pronta resolución. Para la Cámara de Representantes, la opinión al respecto era justamente la contraria: 
La Misión de Estudio del Personal del Comité de Asuntos Exteriores de la Cámara de Representantes de 1982 observó que el cambio cualitativo en la asistencia militar que Estados Unidos está proporcionando bien puede tener un impacto negativo en el logro de una solución política en el Sáhara Occidental ${ }^{29}$.

El aumento de la ayuda militar norteamericana quedó bien reflejado en la información que nos suministra Diego Aguirre en su libro ya citado. En 1974 la venta pasó a 8,2 millones y su ritmo fue ascendiendo hasta 80 millones para el año 1987. Junto a esto ascendían las garantías de crédito que pasó de 14 millones en 1975 a 38 en 1984. El envío de los halcones de la administración al terreno era una clara señal del compromiso guerrero de Reagan en favor de Hasán II. Mandó al general Vernon Walter, quien había ya estado involucrado en operaciones oscuras en países latinoamericanos y en España (Walters, 1981).

La ayuda militar alcanzó los 100 millones en 1983 y los "militares marroquíes recibían instrucción especial en EE UU. A lo ya comentado, Marruecos pudo adquirir 380 misiles Maverick aire tierra y 18 helicópteros Bell” (Diego Aguirre, 1991). Todo esto es lo que se puede considerar el plan Reagan para el proceso de paz en el Sáhara Occidental.

La estrategia asesorada e implementada con la ayuda franco-americana de los muros fue la que tuvo un papel central en el cambio de suerte en la guerra. Se aprobó levantar esas fortalezas ante la evidencia de que era imposible una victoria militar sobre el Polisario, y que en consecuencia lo que se tenía que hacer era desactivar sus apoyos, alejar a la población de sus guerrilleros y tratar de impulsar políticas de desarrollo económico en la zona ocupada. Esto sólo se logró a medias porque los beneficios de las inversiones millonarias en el Sáhara fueron a parar a los colonos marroquíes y no a la población originaria. El aumento de los efectivos militares llevado a cabo con la ayuda norteamericana triplicó los efectivos pasando de 55.000 a 171.000 a lo largo de los ochenta (Harvey, 1988).

Los asesores franceses enseñaron formación contrainsurgente a los militares de Marruecos. Cuando el deterioro de las posiciones marroquíes parecía amenazar el control de Hasán II y se temía por su caída, el asesoramiento francés fue fundamental. Los enormes apoyos que había recibido el ejército marroquí en formación, armas y tecnologías no habían podido parar las ofensivas del Polisario. Todo hacía prever que el régimen se vendría abajo. Fue entonces cuando los franceses, según asevera el coronel Derek Harvey en su obra citada, ponen en práctica su experiencia en la guerra de Argelia y plantean a Marruecos la necesidad de levantar los muros. La estrategia consistía en aislar a los guerrilleros del Polisario de su retaguardia y negarles el apoyo de la sociedad saharaui. Los franceses se inspiraron en Mao para elaborar su teoría de la contrainsurgencia:

Mao Tse-tung combinó una excelente comprensión de las antiguas reglas de la guerra de guerrillas con el talento organizativo y el celo ideológico de un comunista inteligente. Los numerosos escritos de Mao sobre el tema de la guerra de guerrillas revolucionarias vuelven una y otra vez a ser un tema central: la guerra

29 Ver https://mepc.org/journal/united-states-and-western-sahara-peace-process 
de guerrillas, una herramienta de los militarmente débiles, sólo puede tener éxito si es también una guerra popular (Ambler, 1966, p.151).

Francia había tratado de poner en práctica esa enseñanza en la guerra de Argelia, aunque no había funcionado como ellos esperaban. Le Morice Line pretendió aislar a los guerrilleros de sus bases de apoyo sin lograr el objetivo deseado (Storr, 2009). Pero en el caso del Sáhara Occidental, con otras condiciones geográficas y demográficas, la estrategia sí funcionó. La estrategia militar integral consistía en proteger las infraestructuras y proporcionar mejoras a las poblaciones sostén de las guerrillas. Mao lo había escrito en estos términos, "sin bases de apoyo, la guerra de guerrillas no podrá durar mucho tiempo ni desarrollarse; estas bases constituyen precisamente su retaguardia" (Mao Tse Tung, 1974, p.91). Los muros fueron la herramienta clave para separar a los guerrilleros de sus bases de apoyo en los territorios ocupados.

\section{Conclusiones}

La guerra en el Sáhara Occidental estuvo en los primeros años decantada del lado saharaui. Los guerrilleros acometieron importantes ofensivas y llegaron a ocupar más del $85 \%$ del territorio que reivindicaban. Marruecos estaba a la defensiva. Su ejército, infinitamente superior en hombres y armamento, sufría derrotas consecutivas y era incapaz de asentar su dominio sobre los territorios reivindicados, y eso a pesar de contar siempre con un gran apoyo de Francia, de las potencias del Golfo, y el respaldo nada baladí de los EE UU del gobierno Carter. La estrategia de Carter a medio camino entre, diplomáticamente, quererse mostrar neutral, pero en la práctica aumentar las ayudas a Marruecos, no fue definitoria. Los republicanos de su país lo criticaron por ello y por considerar que su política exterior era demasiado contenida y dejaba el terreno libre para que los soviéticos ampliarán sus zonas de influencia.

La derecha norteamericana eligió como aliado clave a Hasán II en el norte de África para contener a Gadafi, el influjo de la revolución iraní y los deseos hegemonistas de los soviéticos, según el argumentario de los gobiernos republicanos. EE UU contemplaba debilidad en el régimen de Hasán II, y temía que un revés en la guerra pudiera significar también el final de su reinado y la entronización de un nuevo poder en Marruecos, que ellos preferían evitar a toda costa para no aventurarse a que Marruecos dejase de ser un aliado fiable si el rey caía.

Pero no fue hasta la llegada del gobierno de Reagan, en enero de 1981, cuando la intensificación de la ayuda financiera y militar experimentó un gran salto cuantitativo y cualitativo, lo que permitió a Hasán II comenzar a asentarse sobre la mayoría del territorio del Sáhara Occidental. La generosa ayuda americana sumada a la de Francia y a la de los países del Golfo fue acompañada por la construcción de los muros de defensa, una estrategia de guerra muy efectiva en la zona en disputa.

Los muros pretendieron dejar al pez sin el agua, separar a los guerrilleros de su pueblo, que eran sus bases de apoyo, y eso resultó definitivo durante la década de los ochenta, sino para garantizar el triunfo de Marruecos, sí para dejarlo en una posición ventajosa sobre el terreno. Los muros, dada su naturaleza de estrategia defensiva, sirvieron para impedir la derrota marroquí, pero no para garantizar su triunfo, de tal manera que la guerra llegó a una situación de impasse, de la que pretendió aprovecharse la monarquía alauita al considerar que el desgaste afectaría más pronto 
y más intensamente a la población saharaui refugiada en los campos de Tinduf y a los propios guerrilleros polisarios que a Marruecos. No parece por el momento, y tras cuatro décadas de haberse implementado esta estrategia, que el plan funcionara para derrotar definitivamente al Frente Polisario.

Sin embargo, la llega de Trump a la presidencia de los EE UU y el reforzamiento de las alianzas con Israel, coronada con el traslado de la embajada a Jerusalén en mayo de 2018 y el posterior reconocimiento de la soberanía marroquí sobre el Sáhara Occidental, ha vuelto a poner de manifiesto la interrelación de estos dos conflictos. El desencadenamiento de las hostilidades nuevamente, ha venido acompañado de un enorme apoyo militar y diplomático a Marruecos. Los ejercicios militares se suceden en la zona con participación de los ejércitos de los dos países. Las últimas maniobras denominadas African Lion 21, desarrolladas en mayo de 2021, han traspasado límites hasta hora vírgenes. Las maniobras se acercarán a escasos tres kilómetros de los campamentos de refugiados de Tinduf en Argelia, y son un aviso contundente de la apuesta norteamericana, ahora con el presidente demócrata Joe Biden, a favor de Marruecos.

\section{Referencias}

Ahmed Omar, E. (2017). El movimiento nacionalista saharaui. De Zemla a la Organización de la Unidad Africana. Madrid: Mercurio.

Ambler, J. S. (1966). The French Army in Politics 1945-1962. Columbus, OH: Ohio State University Press.

Amin, S. (2011). ¿Primavera árabe? El mundo árabe en la larga duración. Barcelona: El Viejo Topo.

Balta, P. (1994). El gran Magreb. Desde la independencia hasta el año 2000. Madrid: Siglo XXI.

Bárbulo, T. (2017). La historia prohibida del Sáhara Español. Las claves del conflicto que condiciona las relaciones entre España y el Magreb. Barcelona: Península.

Damis, J. (1983). Conflict in northwest Africa: The Western Sahara Dispute. Stanford: Hoover Press.

Damis, J. (1993). The United States and North Africa. En W. Zartman y W. M. Habeeb (eds.), Polity and society in contemporary North Africa (pp. 221-241). Boulder, CO: Westview Press.

De Dalmases, P.-I. (2010). Huracán sobre el Sáhara. Barcelona: Editorial Base.

Diego Aguirre, J. R. (1991). Guerra en el Sáhara. Madrid: Istmo.

Diouri, M. (1992). ¿A quién pertenece Marruecos? Barcelona: Límite.

Fuente Cobo, I., y Mariño Menéndez, F. (2006). El conflicto del Sáhara Occidental. Madrid: Ministerio de Defensa/Instituto de Estudios Internacionales y Europeos Francisco de Vitoria.

Feliu, L. (2013). Estados Unidos y el Sáhara Occidental. Una perspectiva histórica sobre la autodeterminación y derechos humanos. RIPS. Revista de Investigaciones Políticas y Sociológicas, 12(2), 159-177.

Fernández Molina, I. (2013). La interacción entre la gestión interna e internacional del conflicto del Sahara Occidental por parte de Marruecos: una propuesta de cronología (19992013). RIPS. Revista de Investigaciones Politicas y Sociológicas, 12(2), 19-43.

Generación Saharaui de la Amistad. (2012). La primavera saharaui. Escritores saharauis por Gdeim Izik. Madrid: Bubok Publishing. 
Gliber, D. M. (2009). International Military Alliances, 1648-2008. Washington: CQ Press.

González del Miño, P. (2014). Tres años de revoluciones árabes. Madrid: Catarata.

Gourdon, J. (1972). Chronique politique : Maroc. En Annuaire de l'Afrique du Nord 10 (pp. 322-334). París: Éditions du CNRS.

Harvey, D. (1988). The Reagan doctrine, Morocco, and the Conflict in the Western Sahara: An Appraisal of United States Policy (Tesis de Máster). The University of Utah, Estados Unidos.

Hodges, T. (1984). The Western Sahara (Report, $\mathrm{n}^{\circ}$ 40). Londres: The Minority Rights Group.

Hughes, S. O. (2001). Morocco under King Hassan. Reading (Inglaterra): Ithaca Press.

Laroui, A. (2007). Marruecos y Hasán II: Un testimonio. Madrid: Siglo XXI.

Lacouture, J. (1972). Nasser. Barcelona: Dopesa.

Mao Tse Tung. (1974). Obras Escogidas (Tomo II). Madrid: Fundamentos.

Marquina Barrio, A. (1983). El conflicto del Sahara y la cooperación global del gobierno español con Argelia y Marruecos. Revista de Estudios Internacionales, 4(4), 755-773.

Martín Beristain, C., y González Hidalgo, E. (2009). El oasis de la memoria. Memoria histórica y violaciones de los derechos humanos en el Sáhara Occidental. Donostia/San Sebastián: UPU/EHU, Hegoa.

Martín Beristain, C; Martínez Torres, A.; Valencia Villa, A., y Campo Lladó, S. (2015). Los otros vuelos de la muerte. Bombardeos de población civil en el Sáhara Occidental. Bilbao: UPU/EHU, Asociación de Amistad con el Pueblo Saharaui de Sevilla.

Ould Daddah, M. (2012). Mauritania contra viento y marea. Memorias. Madrid: Catarata / Casa África.

Prashad, V. (2012). Las naciones oscuras. Una historia del Tercer Mundo. Barcelona: Península.

Perrault, G. (1991). Nuestro amigo el Rey. Barcelona: Plaza \& Janés

SSI (Strategic Studies Institute). (2013). War and Insurgency in Western Sahara. Carlisle Barracks, PA: U.S. Army War College.

Storr, D. (2009). A Line in the Sand. Norfolk, VA: Joint Forces Staff College Joint Advanced Warfighting School.

Villar, F. (1982). El proceso de autodeterminación del Sáhara. Valencia: Fernando Torres Editor.

Walters, V. A. (1981). Misiones discretas. Barcelona: Planeta.

Willis, M. J. (2014). Politics and power in the Maghreb. Algeria, Tunisia and Morocco from Independence to the Arab Spring. Londres: Hurst \& Co.

Wright, J. C. (1985). The King and the Shah: Modernisation, dependence and regime stability. Monterey, CA: Naval Postgraduate School.

Yousfi, R. H. (2014). Aiding and Abetting: The Illegality of Morocco's Nationalist Expansion into Western Sahara and their Support from the United States (Tesis de Máster). University of San Francisco, California, Estados Unidos.

Zoubir, Y. (1987). Soviet Policy in the Maghreb. Arab Studies Quarterly, 9(4), 399-421.

Zoubir, Y., y Amirah-Fernández, H. (eds.). (2008). North Africa: Politics, Region, and the Limits of Transformation. Londres: Routledge.

Zoubir, Y., y Hamadouche, L. D.-A. (2013). Global Security Watch - The Maghreb: Algeria, Libya, Morocco, and Tunisia. Santa Barbara, CA: ABC-CLIO, LLC. 


\section{Fuentes consultadas:}

(Las fuentes primarias consultadas han sido en su totalidad norteamericanas. Albergan una cantidad muy importante de documentos referidos a la temática que se aborda aquí).

CIA historical-collections

NARA

The Reagan Library

The Carter Library 